\title{
DEVELOPMENT OF AN ADVANCED PRESSURE SIGNAL ACQUISITION CARD FOR A MODULAR TURBOJET FADEC SYSTEM
}

\author{
Károly BENEDA* \\ Budapest University of Technology and Economics, Faculty of Transportation Engineering and \\ Vehicle Engineering, Department of Aeronautics and Naval Architecture \\ *Corresponding author. E-mail: beneda.karoly@kjk.bme.hu
}

\begin{abstract}
Gas turbine engines are very important in aviation. Pressure is one of the key thermodynamic parameters which, first of all, suffers radical change within the flow passage of a gas turbine, on the other hand, there are several accessories like fuel and oil supply, in which the pressure of the working medium is essential. The measurement of this variable is therefore inevitable in data acquisition or engine control systems. The author shows the process of development of an advanced pressure signal acquisition card that fits into a modular electronic control system of a turbojet engine. The unit incorporates numerous experiences gathered with the previous generation of this module regarding power supply and integrated sensors as well. Furthermore, there are several innovations that enable a more efficient installation, data acquisition and built-in test possibilities. The most important difference is the 32-bit ARM Cortex-M0+ microcontroller which allows faster operation which allows the acquisition of more signals, including additional functions as thrust measurement, digital input/output handling and many others. The unit operation was thoroughly assessed using simulated and real operating conditions as well.
\end{abstract}

Keywords: micro gas turbine; turbojet; pressure sensing; FADEC; data acquisition

\section{INTRODUCTION}

Gas turbine engines are very widely used in various fields of industry; hence their safe and economical operation is rather important. Especially in aviation, turbine engines are utilized for main propulsor of the aircraft, mostly in the form of either high bypass ratio turbofan or turboprop configuration. In the early years of turbine propulsion, turbojets were used, but nowadays - due to their moderate propulsive efficiency at low Mach numbers - they are quite rarely found. However, there are some cases where their simplicity overcomes the previously mentioned drawbacks. These special roles include military drones [1], hobby radio-controlled aircraft [2]; furthermore, they can be used as test bed for different research purposes [3,4]. In many cases, the data obtained on a turbojet engine can be used on larger, more complex engine types, due to the similar basic operating principle $[5,6]$.

At the Department of Aeronautics and Naval Architecture, there is a single stream, single-spool turbojet engine with variable area exhaust nozzle, type TKT-1. This unit serves already for more than ten years for research and education purposes. It also features a modular, full authority digital electronic control (FADEC) system, which was previously presented by the author [7]. Due to the experiences with the previous generation of pressure measurement electronics and constantly growing demand for increased number of monitored parameters, a new pressure measuring card was developed. The article introduces the reader into this process, beginning with the brief description of the original system, afterwards it presents the hardware and software aspects of the newly built unit. Moreover, the testing of the device is illustrated, which included both assessment with simulated signals and verification of correct operation under real circumstances. Finally, the author gives a conclusion based on the acquired experience with the new system. 


\section{DESCRIPTION OF THE PRESSURE MODULE}

This section gives a comparison of the new module in contrast to the original system, afterwards the details of the developed unit are described.

\subsection{Summary of the framework}

The modular FADEC for the TKT-1 is based on a custom-built motherboard with six receptacles in which different electronic cards can be inserted. Besides the main power supply which consist of 24 VDC and ground lines, there is a controller area network (CAN) bus to which all modules are connected in order to allow exchange of all necessary data. During initial tests the bus speed was limited to 10 $\mathrm{kbps}$, but it has been increased to nearly $200 \mathrm{kbps}$ as the number of messages was increased due to the broadened functionality and larger amount of monitored parameters. The development of this unit was described in more details in [7].

In the original concept, the system consisted of two main controller cards, one unit dedicated to pressure and one for temperature measurement, finally, a fifth device that is necessary to organize the operation and provide built-in test functions. However, the last circuit was not realized yet, as it was not essential for the basic operation of the system. Similarly, only a single controller card has been built, i.e., the layout is a single FADEC yet, the fully functional dual FADEC system is considered as a subsequent further development in the close future. It has to be mentioned, that at the time of the initial development, which lasted from 2009 to 2014, the system was based on a legacy 8-bit microcontroller of type NXP (formerly Freescale) MC9S08DZ60. This was selected as a standard MCU, which was then used in every different card. In the recent years, however, it was found that this type has such limitations, which could be eliminated with the introduction of more powerful MCU.

The layout and the appearance of the original system can be found in Fig. 1. In Fig. 1/a), the digital CAN bus evidently defines how the analog parameters of the gas turbine operation should be handled, i.e., the main function of the pressure (and thermo) module is to acquire and digitize these appropriate signals arising throughout the operating envelope of the gas turbine.
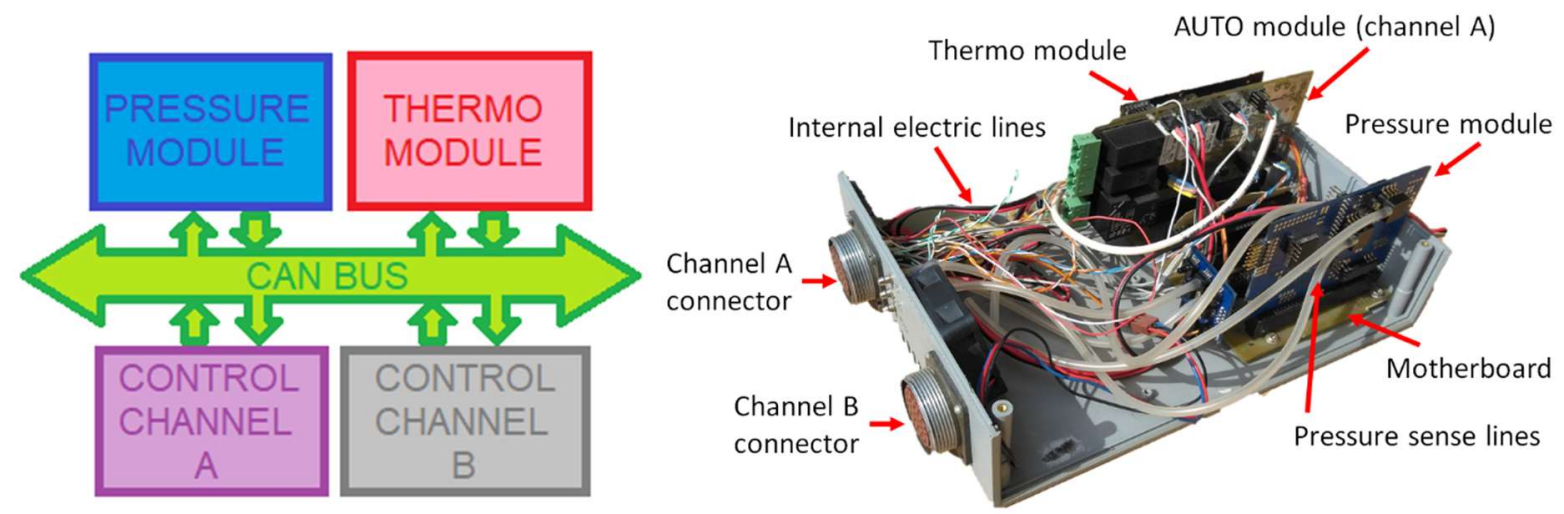

Figure 1 Theoretical layout of FADEC system of TKT-1 (a) and its realization (b). Source: own work of the author.

\subsection{Description of the original pressure module}

The very first version of the pressure module, which was named as M250A after the highest gauge pressure in the compressor, contained only pressure sensors and their analog output was routed to the motherboard. This concept was soon abandoned, realizing the possible disturbances to the analog signals, however, the created circuit was used until 2016 when the original Advantech ADAM data acquisition modules were phased out. For this reason, it is not detailed further.

As it was mentioned previously, the next version of the electronic unit, called M250B, was built around the NXP MC9S08DZ60 MCU (abbreviated as DZ60 hereafter), from which the 32-pin LQFP version was 
selected. This device features a 12-bit analog-to-digital converter with 10 externally available channels, this was the maximum amount of independent pressure signals that can be monitored. The other pins were connected to a header for spare digital functions, but these have not been used in practice. The motherboard configuration was also changed, no analog signals were passed through it, the data exchange is solved by CAN communication and some extremely important digital lines.

The pressure sensors were selected similarly from NXP, mainly the MPX4xxx, MPX5xxx and MPX7xxx families were used. These are generally suitable for air and other non-corrosive, non-aggressive materials. Therefore, pressures only from the gas turbine flow path were considered for monitoring. The sources can be seen in Tab. 1, where a comparison is made with the newest standard, the M250C. As a convention, the last three digits of sensor type designation shows the limit pressure in kilopascals, "DP" stands for dual ported, "GP" shows gauge ported, "AP" indicates axially ported versions. The original MPX series show a large, through-hole mounted sensor, MPXV is a surface mounted device with 5 VDC power supply, and the MP3V series are supplied from 3 VDC. Finally, MPX[H/A]Z sensors have a very little surface mounted form factor, therefore they had priority in the new design.

Table 1 Comparison of pressure signals handled by M250B and $-\mathrm{C}$ versions. Source: author's own work.

\begin{tabular}{|c|c|c|c|c|c|}
\hline \multicolumn{2}{|c|}{ Pressure signal } & \multirow[b]{2}{*}{ M250B } & \multicolumn{3}{|c|}{ M250C } \\
\hline Description & Symbol & & Sensor type & $\begin{array}{c}\text { Nominal/ } \\
\text { overload } \\
\text { capacity (kPa) }\end{array}$ & $\begin{array}{l}\text { Max. } \\
\text { error } \\
(\% \mathrm{FS})\end{array}$ \\
\hline Ambient pressure & $\mathrm{p}_{0}$ & \multicolumn{2}{|c|}{ MPXHZ6115A } & $15 \ldots 115 / 400$ & \pm 1.5 \\
\hline $\begin{array}{c}\text { Inlet orifice } \\
\text { pressure drop }\end{array}$ & $\Delta \mathrm{p}_{\mathrm{o}}$ & \multirow{2}{*}{ MPXV7002DP } & \multirow{2}{*}{ MPXV7007DP } & \multirow{2}{*}{ $\pm 7 / 75$} & \multirow{2}{*}{ \pm 5.0} \\
\hline $\begin{array}{l}\text { Compressor inlet } \\
\text { total pressure }\end{array}$ & $\mathrm{p}_{1 \mathrm{t}}$ & & & & \\
\hline $\begin{array}{l}\text { Surge suppression } \\
\text { chamber pressure }\end{array}$ & $\mathrm{p}_{\mathrm{SC}}$ & MPXV7025DP & MP3V5050DP & $0 \ldots 50 / 200$ & \pm 2.5 \\
\hline $\begin{array}{l}\text { Impeller discharge } \\
\text { static pressure }\end{array}$ & $\mathrm{p}_{1.5}$ & \multirow{2}{*}{ MPX4250GP } & \multirow{5}{*}{ MPXAZ6400A } & \multirow{5}{*}{$20 \ldots 400 / 1600$} & \multirow{5}{*}{ \pm 1.5} \\
\hline $\begin{array}{l}\text { Impeller discharge } \\
\text { total pressure }\end{array}$ & $\mathrm{p}_{1.5 \mathrm{t}}$ & & & & \\
\hline $\begin{array}{l}\text { Compr. discharge } \\
\text { static pressure }\end{array}$ & $\mathrm{p}_{2}$ & - & & & \\
\hline $\begin{array}{l}\text { Compr. discharge } \\
\text { total pressure }\end{array}$ & $\mathrm{p}_{2 \mathrm{t}}$ & - & & & \\
\hline $\begin{array}{l}\text { Turbine inlet } \\
\text { total pressure }\end{array}$ & $\mathrm{p}_{3 \mathrm{t}}$ & - & & & \\
\hline $\begin{array}{l}\text { Turbine discharge } \\
\text { static pressure }\end{array}$ & $\mathrm{p}_{4}$ & \multirow{2}{*}{ MPXV5050DP } & \multirow{2}{*}{ MP3V5050DP } & \multirow{2}{*}{$0 \ldots 50 / 200$} & \multirow{2}{*}{ \pm 2.5} \\
\hline $\begin{array}{l}\text { Turbine discharge } \\
\text { total pressure }\end{array}$ & $\mathrm{p}_{4 \mathrm{t}}$ & & & & \\
\hline $\begin{array}{l}\text { Turbine discharge } \\
\text { flow direction }\end{array}$ & $\Delta \mathrm{p}_{4, \mathrm{dir}}$ & \multicolumn{2}{|c|}{ MPXV7025DP } & $\pm 25 / 200$ & \pm 5.0 \\
\hline $\begin{array}{l}\text { Pressure of } \\
\text { control air }\end{array}$ & $\mathrm{p}_{\mathrm{c}}$ & MPX4250GP & MPXAZ6400A & $20 \ldots 400 / 1600$ & \pm 1.5 \\
\hline $\begin{array}{l}\text { Fuel pressure, } \\
\text { pump outlet }\end{array}$ & $\mathrm{p}_{\mathrm{f} 1}$ & - & TC716-277 & $\begin{array}{c}0 \ldots 40 \mathrm{bar} / \\
60 \mathrm{bar}\end{array}$ & \pm 0.5 \\
\hline $\begin{array}{c}\text { Fuel pressure, } \\
\text { nozzle inlet }\end{array}$ & $\mathrm{p}_{\mathrm{f} 2}$ & - & WIKA A10 & $\begin{array}{c}0 \ldots 25 \mathrm{bar} / \\
50 \mathrm{bar}\end{array}$ & \pm 0.5 \\
\hline $\begin{array}{l}\text { Total number of } \\
\text { signals: }\end{array}$ & - & 10 & 15 & - & - \\
\hline
\end{tabular}


As it is evident from Tab. 1, the newly developed board has one and half times more pressure signals in contrast to its predecessor, many of which have arisen in the recent years of the turbojet research. In Tab. 1, those pressures, which represent a total value from the respective station, are marked with " $t$ " in the lower indices. The last columns indicate nominal and overload capacity, as well as the maximum error budget of a given sensor expressed in the percentage of the full-scale voltage.

\subsection{Description of the new pressure module hardware}

Based on the experiences of the former design, there were several aspects, in which the M250C differs from its predecessor, these are shown in the following list.

- Power management: the original M250B uses a standard linear regulator, which drops the inlet voltage of $24 \mathrm{VDC}$ to $5 \mathrm{VDC}$. The large voltage is necessary due to various valves in the system, meanwhile electronics use the lower voltage. Nevertheless, as the sensors draw significant amount of current of around $100 \mathrm{~mA}$, the wasted power increases the temperature of the regulator to considerably high values around $80^{\circ} \mathrm{C}$. This is not dangerous, as the limit temperature is $125^{\circ} \mathrm{C}$, but if the linear regulator is changed to an advanced switching DC/DC converter, the dissipated power can be substantially decreased. The selected type of the converter is DCR022405 from Texas Instruments, which has a $2 \mathrm{~W}$ nominal power output from $24 \mathrm{VDC}$ to 5 VDC, i.e., it can supply a maximum of $400 \mathrm{~mA}$.

- New, miniaturized pressure sensors: in order to facilitate the implementation of increased number of sensors within the same geometric constraints, new devices had to be selected. During the recent years, several reduced scale units were developed, which are suitable for the given purposes. According to Tab. 1, in multiple positions the NXP MPXAZ6400AP was used. Two special pressure sensors were also introduced, which monitor the fuel pressure at two distinctive locations, which are important in the viewpoint of system operating conditions, these are pump outlet and injection nozzle inlet pressures. These devices require special materials as they must withstand the aggressive turbine fuel. These two sensors provide $4 . .20 \mathrm{~mA}$ signals, which necessitate slightly different signal connection to the MCU in the form of a shunt resistor.

- Redesigned routing of pressure hoses: in the predecessor, all ported pressure sensors were installed in an upward orientation, i.e., as the pressure hoses that come from the front side of the controller box, they must take a 90-degree turn to connect to the sensors' ports. This introduces a side load on the port, potentially resulting in the mechanical failure of the component, either in the form of a broken port or completely tearing the sensor with the pads from the printed circuit board. This problem was entirely eliminated by designing a small, perpendicular card for those sensors, which have an axial port, to allow straight connection to the hoses, and rotating the other sensors on the main board towards the forward edge. This can be seen in Fig. 2 as well.

- Advanced microcontroller: as the possibilities of the original 8-bit legacy MCU were limited, it was obvious that a new architecture is required. As the demands were not changing in magnitudes, a nearly entry-level NXP MKE06Z128 MCU was selected with 32-bit ARM Cortex-M0+ core. Its main features can be evaluated in Tab. 2, along with the comparable values of the original DZ60. In Tab. 1, the majority of the analog inputs were already listed. However, the 64-pin package, which is used here, offers a total of $16 \mathrm{~A} / \mathrm{D}$ channels. The last one has a special function; the fuel flow meter provides $4 . . .20 \mathrm{~mA}$ output signal, which is connected to this input through a $100 \Omega$ shunt resistor. Similarly to the previous design, the unused pins of the MCU package are routed to pin or socket headers, where additional digital or analog signals can be connected. In contrast to the single connector header on the M250B, on the new design the headers are grouped according to their nature. Thus, there are the following groups realized:

- simple digital input/outputs;

- so-called keyboard interrupts, which are special digital inputs that are able to initiate an interrupt upon the change of the signal level;

- pulse width modulating outputs;

- I2C and SPI communication ports. The latter is already dedicated to an HX711 load cell amplifier/digitizer, that is responsible to monitor thrust signals. 


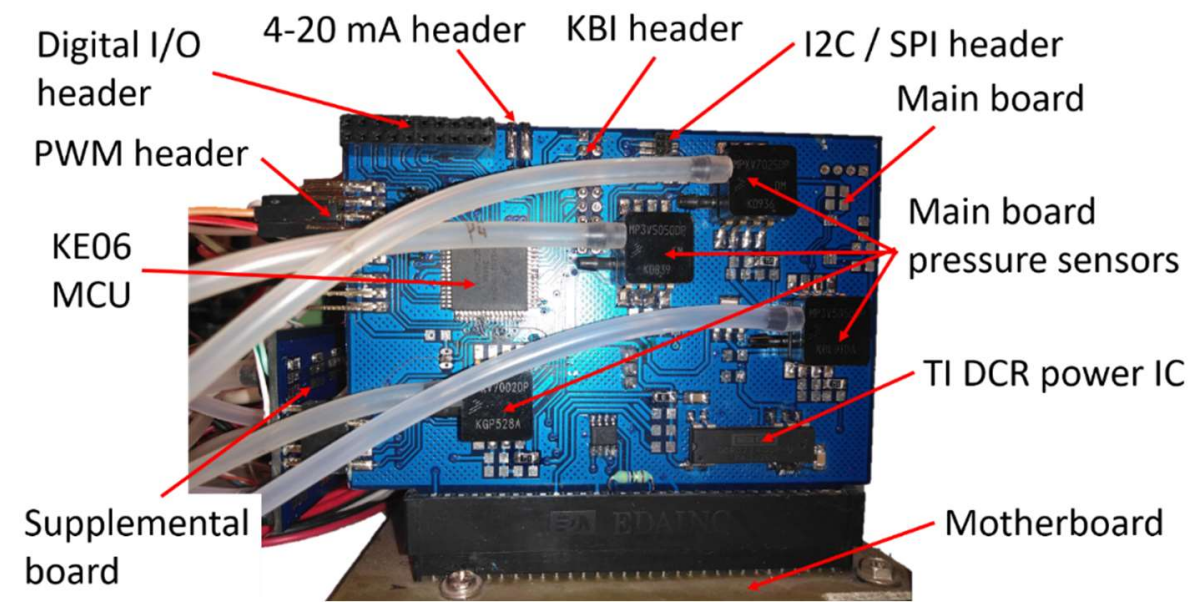

Figure 2 The new M250C module inserted into the motherboard of the FADEC system. Source: author's own image.

Table 2 Comparison of microcontrollers used in M250B and $-\mathrm{C}$ versions. Sources: $[8,9]$

\begin{tabular}{|c|c|c|c|}
\hline Feature & Unit & M250B & M250C \\
\hline Type of MCU & n.a. & MC9S08DZ60 & MKE06Z128 \\
\hline Architecture & n.a. & 8 -bit & 32-bit ARM Cortex M0+ \\
\hline Max. clock frequency & $\mathrm{MHz}$ & 20 & 48 \\
\hline Pin count & - & 32 & 64 \\
\hline Flash memory & $\mathrm{kByte}$ & 60 & 128 \\
\hline RAM & $\mathrm{kByte}$ & 4 & 16 \\
\hline A/D channel count & - & 10 & 16 \\
\hline PWM counters & - & 2 & 2 \\
\hline PWM channels & - & $8(6+2)$ & $8(6+2)$ \\
\hline No. of I2C modules / max baud rate & $-/ \mathrm{kbps}$ & $1 / 500$ & $2 / 1200$ \\
\hline No. of SPI modules / max baud rate & $-/ \mathrm{kbps}$ & $1 / 5000$ & $2 / 12000$ \\
\hline
\end{tabular}

\subsection{Description of the firmware}

The MCU operating firmware remarkably utilizes the nested interrupt capability of the ARM CPU. The main task is the acquisition of the analog signals, which is automatically started by the real time interrupt at every $100 \mathrm{~ms}$, and the $\mathrm{A} / \mathrm{D}$ controller raises an interrupt when the retrieval of the data is finished. This ensures data integrity, i.e., the signal processing is performed only when the new values are already completely obtained. The raw data is then converted to physical parameters, these are then loaded into the CAN transmit buffer one after another. This is the second main task, to broadcast the pressure information on the main bus and in order to prevent interference between individual CAN messages, each message with a unique identifier can be transmitted only when the previous has been transferred and a buffer empty interrupt is occurred.

The real time interrupt (RTI) itself incorporates several secondary functions. It performs the data exchange with the HX711 load cell digitizer, afterwards it initializes the next measurement on this module, which is rather slow in contrast to the other $\mathrm{A} / \mathrm{D}$ conversions, it takes around $250 \mathrm{~ms}$, therefore, this process is carried out in every $5^{\text {th }}$ main cycle only, which also provides some computational overhead.

Additionally, the ADC interrupt accomplishes asynchronous serial transmission according to RS232 of the measured data in order to provide built-in test possibilities, if required. In the development process it was a very useful function that it periodically broadcasts the entire data package. Under normal operating conditions, as the communication between FADEC modules rely solely on the CAN bus, the asynchronous RS232 transmission can be disabled to improve the performance of the module.

Based on the experience with the previous generation, regarding especially the main controller module, which is responsible for the automatic control of the turbojet, an advanced RS232 command set was 
defined and implemented in the main function of the firmware. These commands include offset calibration, fine trimming and many other features that allow high level interaction with the operating firmware.

Besides the previously mentioned tasks, the module is prepared to accept the input signal train from a speed sensor. This is a variable frequency task, which depends always on the actual operating condition of the gas turbine. The delay between two consecutive signals can be theoretically infinity in case of a still standing rotor, or - due to a built-in 8-fold prescaler and the 20 blades of the compressor to be counted - it can reach around $2.1 \mathrm{kHz}$ when the engine runs at $100 \%$, which equals to $50,500 \mathrm{rpm}$. Whenever a signal is sensed, a short interrupt routine is invoked, in which the period is calculated, then a reciprocal is computed to establish the rotor speed. In order to ensure visualization of this essential parameter on reduced integration level gauges, the M250C module also provides a PWM output that gives an output signal of average voltage between 0 and $1 \mathrm{VDC}$, which is proportional to the percentage of the nominal rotor speed, thus a digital multimeter or similar unit can show the speed information.

As an additional task independently from the others, the M250C module also offers a backup manual control of the metering valve in case of main controller failure. For this reason, it receives throttle lever position and provides another PWM output which is then connected to the metering valve driver circuit. This function has a special feature, upon button pressing, the module can carry out a slow acceleration from idle to maximum power with nearly two minutes ramp-up time. This rather slow change of operational conditions allows collecting quasi-steady-state data about the gas turbine.

\section{ASSESSMENT OF THE NEW PRESSURE MODULE}

The investigation of the newly built pressure module was carried out in different steps. First, a LabVIEW software was created to provide a visual representation of the measured data. Then, using the RS232 automatic data transmission, the module was tested alone. Calibration of built-in pressure signals was performed using reference pressures; external units which provide $4 . . .20 \mathrm{~mA}$ signals were substituted by test potentiometers. Afterwards, the card's CAN node was connected to a CAN analyzer, which in turn supplied the data to a comprehensive LabVIEW program, which can monitor the sent messages in the entire FADEC system. The last step of the assessment was executed with the module inserted into the motherboard. This step was divided into two subtasks indeed, in the first step, the engine was not run yet, and finally, a complete inspection under real operating conditions was accomplished.

\subsection{LabVIEW test program for the M250C pressure module}

The software is a simple modification of the basic VISA / RS232 serial communication example with custom front panel that represents the physical realization of the module, and the measured pressures are indicated as symbolic gauges, as seen in Fig. 3.

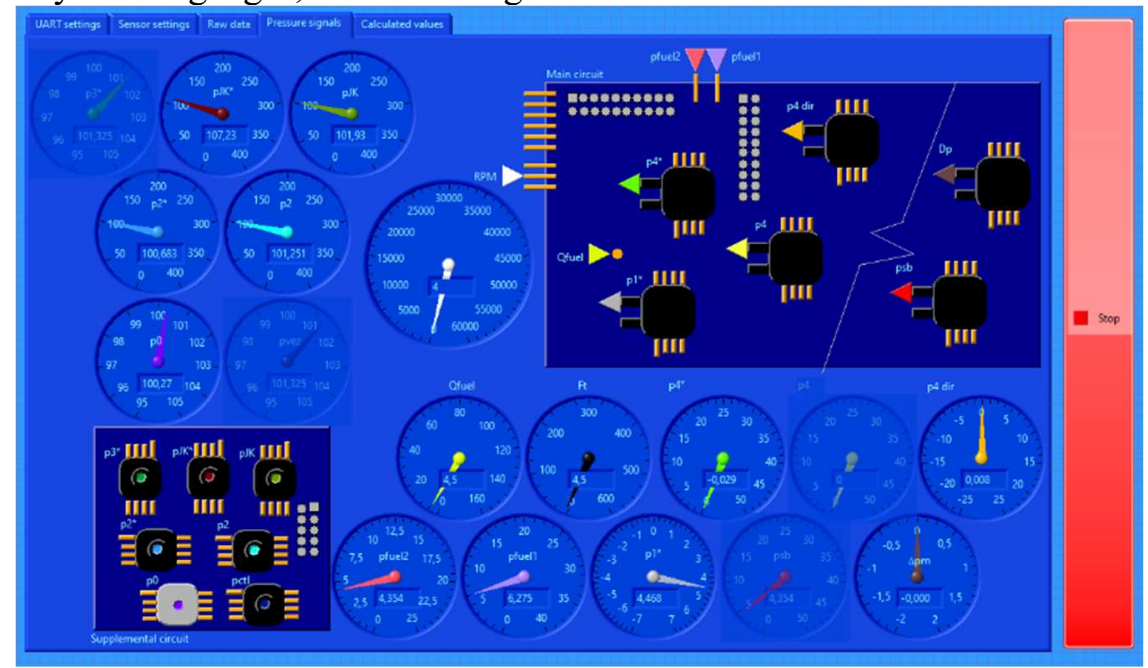

Figure 3 User interface of the LabVIEW RS232 tester program for the pressure module. Source: author's own work 
The information is sent in the form of ASCII text, the program splits the string into parts which form the numeric values and converts them into variables for indication. The software also provides automatic logging of the received data. In the original version, different colours are used to differentiate between the individual pressure signals, the same colours can be found in the centre of the given gauge, and an arrow is put to the port of the given pressure gauge on the symbolic drawing.

Fig. 3 also indicates a tab control, which organizes the main features of the software. Five main tabs can be seen, which are the following:

- UART settings: provides selection for the UART channel to be used, baud rate, and other communication specific items.

- Sensor settings: in the early version of the module firmware, it did not convert the measured raw data into their corresponding physical values, here the user was able to select the appropriate factors, offsets etc.

- Raw data: the UART communication from the M250C is provided in the form of blocks of data sent in every $100 \mathrm{~ms}$. This page simply splits the entire string into the corresponding numeric displays.

- Pressure signals: this page indicates the values in the form of symbolic gauges along with the simplified schematic of the main and supplemental circuits, which show the arrangement of the individual sensors. The present arrangement was important during the individual testing of different transducers, in order to easily identify that unit, which is being tested.

- Calculated values: there are numerous parameters that can be deduced from the pressure signals obtained here. Some of these are compressor pressure ratio, engine pressure ratio, air mass flow rate, etc.

Besides the real time indication, the program automatically logs the data into a text-based spreadsheet file, which can be evaluated in any commercial software like Excel after the measurement is completed.

\subsection{Circuit and LabVIEW test program for the entire FADEC}

After creating a software for the single pressure module which was able to read the communication from the RS232 channel, another program was realized in order to monitor all the messages sent through the CAN bus. The hardware, which is necessary to perform this task, is an NXP mbed LPC1768 prototyping card inserted into a breadboard along with a TI SN65HVD251 CAN transceiver in a standard DIP8 package to provide level shifting between TTL and CAN. Then, a simple firmware was written through the mbed.org online compiler, which transfers the received CAN frame information to the mbed's USB serial port. As this unit establishes a connection with the main CAN bus on the motherboard, it is able to fetch all messages sent, even if they are broadcasted by other modules, like temperature measurement card. The corresponding LabVIEW software similarly represents the data in an easily readable format. It also provides an interface, where the raw data can be seen, and there is another page of the tab control, which represents the gas turbine itself surrounded by data originating from the different locations. Fig. 4 shows the view of the software.

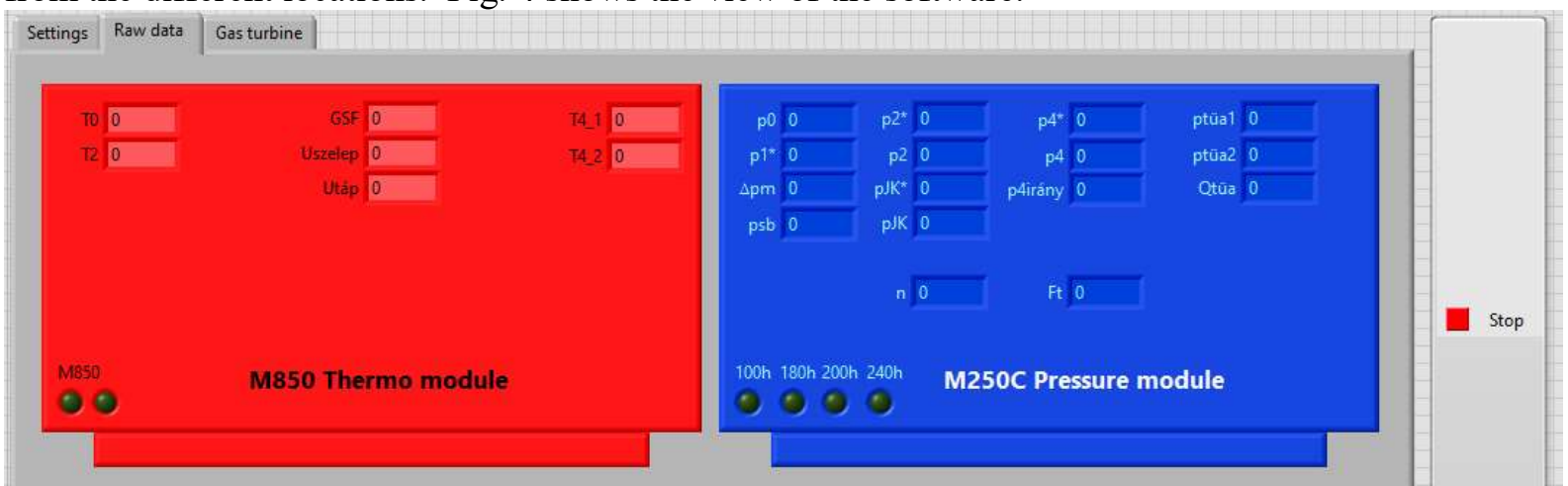

Figure 4 Screenshot of LabVIEW CAN monitoring software. Source: author's own work 


\subsection{Test run of the turbojet engine}

After the preliminary tests have all succeeded, the entire system was assessed under real operating conditions. The engine test run was performed outdoors on the yard of the laboratory.

After the engine was started, a short delay was performed to allow warmup of turbine components. Subsequently, a special operating mode has been selected, which simulates a consistent $1 \%$ throttle increase per second instead of human interaction. After this program has concluded, manual control was regained, there were multiple throttle changes until shutdown.

Fig. 5 shows the large pressures around the compressor, i.e., static and total pressures from the impeller outlet and the stage outlet. It is very interesting, how much of the pressure is wasted in the vaned diffuser of the compressor, before it leaves the stage.

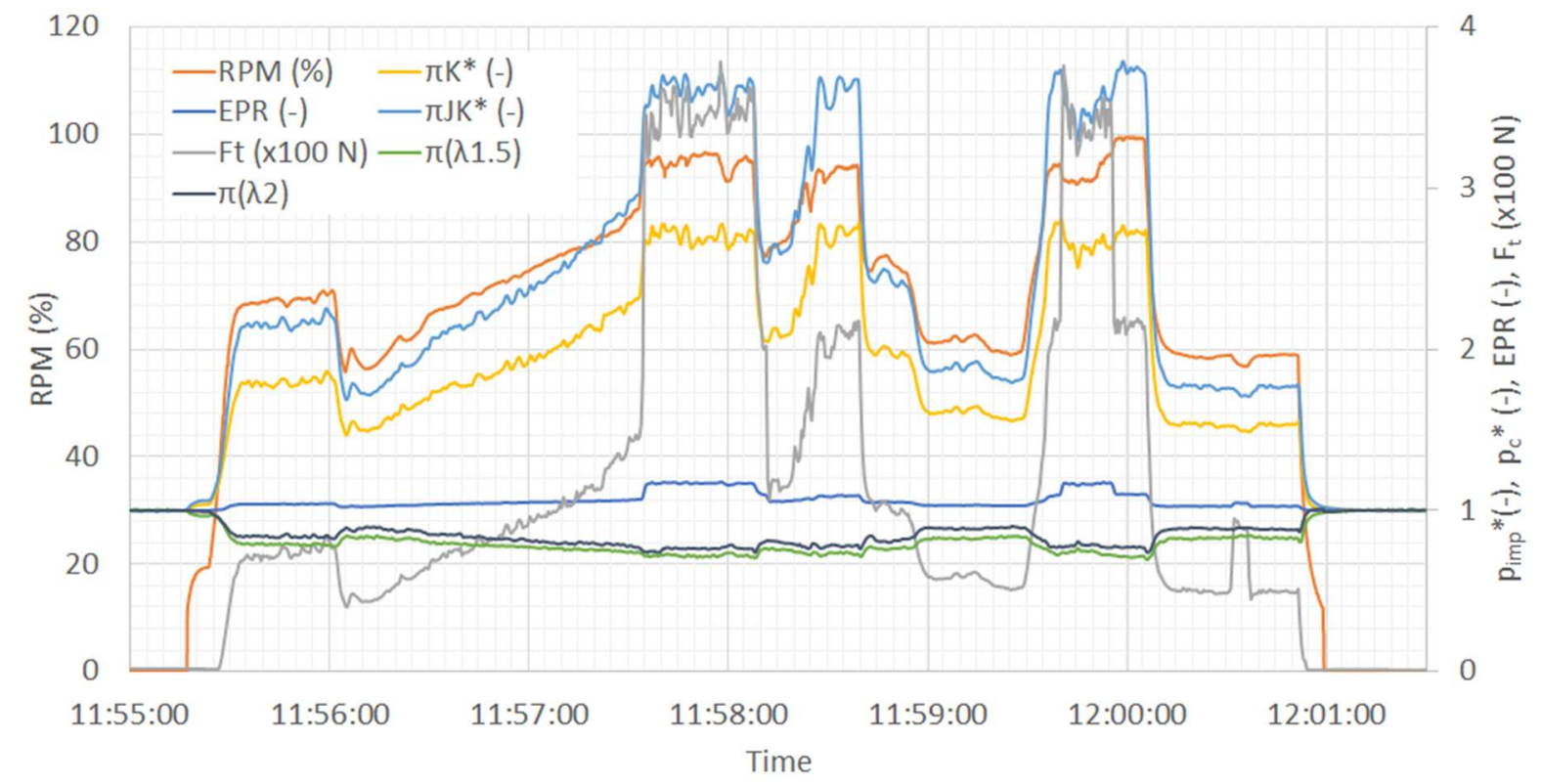

Figure 5 Compressor pressures throughout the entire engine test run. Source: author's own work.

Next, the fuel related variables can be evaluated. This can be performed using the time series depicted in Fig. 6. When focusing on the fuel volumetric flow $Q_{f}$, it must be noted that it consists of a small and sensitive turbine wheel, which may begin to rotate under significant vibration even without real flow, thus generating false signals. This can be seen during the initial cranking phase of the starting, when no fuel pressure is present in the system, however, the fuel flow already gives an indication. Later, when the engine is already fed, there are still some discrepancies, in contrast to the green line, which represents the fuel nozzle pressure, which theoretically should be proportional to the flow. The difference is due to the integrating nature of the flow sensor, i.e., its output does not immediately change if there is a variation in the incoming flow. This explains the delay of the flow signal in contrast to the pressures.

In Fig. 6, other interesting phenomena can be identified. During the autonomous ramp-up of the throttle, at around 11:57:30 one can observe a sudden increase in all main parameters. This is due to the pressure relief valve built into the pump unit type 924, which opens at a level which is set by a manual adjuster screw. The pump unit was recently replaced, and the adjustment was not correct, which shall be tuned later in order to give a straight correlation between throttle input and rotor speed.

One can also recognize the large pressure peaks at the beginning and at the end of the time series regarding $p_{f l}$, which is the fuel pump outlet pressure. The sudden rise is linked to the closed state of the high pressure shutoff valve, which prevents the flow into the combustion chamber before the turbine reaches the required speed during startup, and after the shutdown command was received. During these 
time periods, the pump is (still) operating, but the fluid can only escape through the pressure relief valve. Thus, a pressure peak appears whenever this condition is found. Note that $p_{f 2}$, nozzle pressure is zero at these intervals, showing no flow to the combustion chamber.

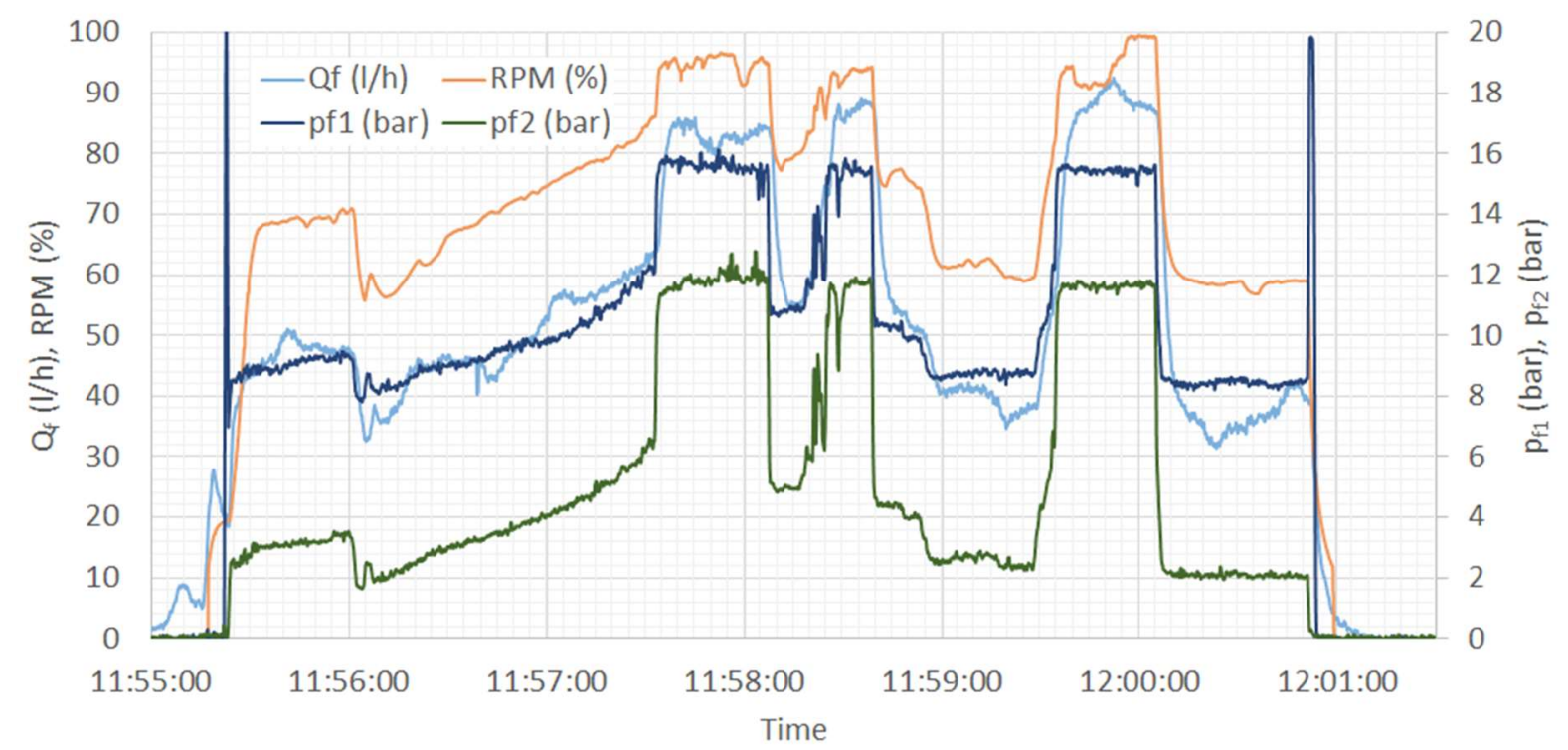

Figure 6 Time series of fuel pressures and fuel flow. Source: author's own work.

Finally, if one evaluates the air pressures, then different pressure ratios can be drawn. These are indicated in Fig. 7, on which EPR, thrust and dimensionless pressure ratios $\pi\left(\lambda_{1.5}\right)$ and $\pi\left(\lambda_{2}\right)$ also appear. If one compares the former two time series, it can be easily seen, how the stator vanes slow down the airflow as it approaches the compressor discharge. One can note that the EPR is rather small, however, there are some sudden changes in this variable, which is in turn followed by the rise of the thrust output. The TKT-1 is equipped with a variable exhaust nozzle, which was closed during these short time periods.

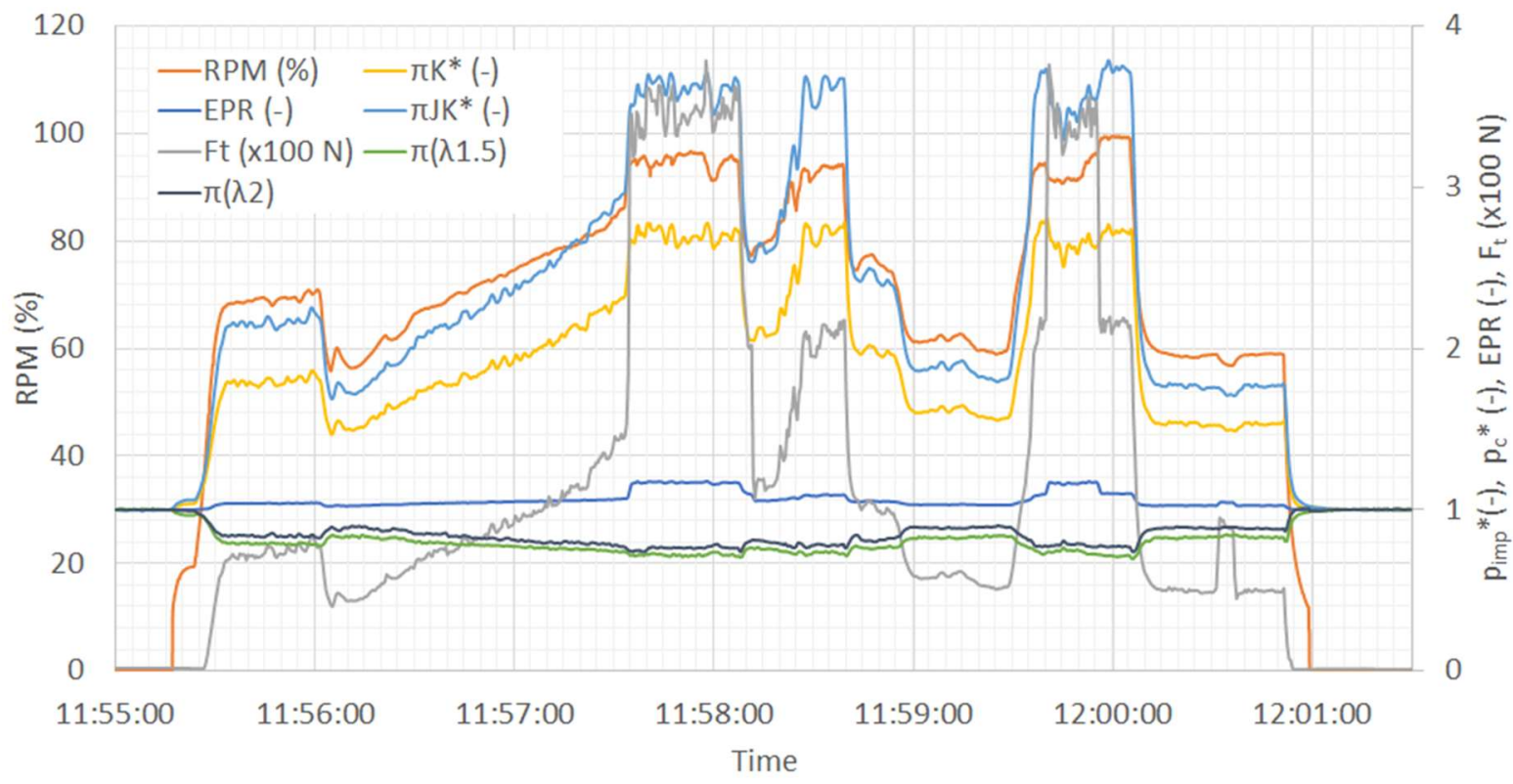

Figure 7 Time series of calculated pressure ratios and thrust of the turbojet. Source: author's own work. 


\section{CONCLUSION}

As it was presented in the previous sections, the newly developed pressure module fulfils all the previously determined tasks; furthermore, it is still capable of increasing its range of features.

It has been designed using a decade long experience with the legacy 8-bit microcontrollers, but as it is based on 32-bit technology, it offers much more possibilities.

The preliminary testing was performed through a comprehensive sequence, which included multiple steps to provide different aspects and levels of technology readiness. After the hardware reached the full functionality, the development of the operating firmware was begun. Together with this work, the creation of various testing software was realized to verify correct operation and enable data acquisition.

Finally, the pressure module was tested under real operating circumstances, besides some technical issues that have to be solved later, the operation of the module itself was more than satisfactory.

Even if the present pressure module reached a useable level, the entire FADEC is considered to be ready for improvement. This further development shall include the design of an advanced temperature sensing module, directly based on the newly gathered experience with the first ARM-based board. Regarding the control module, an intermediate solution is under development, which would not be a fully independent standalone circuit, rather an adaptor board into which a complete mbed LPC1768 fast prototyping unit can be inserted. Thus, one can benefit from the rapid application development on a higher-level ARM Cortex-M3 microcontroller that can reach up to $100 \mathrm{MHz}$ clock, which is double in contrast to that of the newly introduced Kinetis KE06. Regarding the organizing and interacting function of the main controller circuit, the utilization of a more advanced CPU seems necessary.

\section{References}

[1] Işı, G. - Ekici, S. - Şahin, G. A neural network model for UAV propulsion system, Aircraft Engineering and Aerospace Technology. 2020. Vol. 92 No. 8, pp. 1177-1184. doi: 10.1108/AEAT-042020-0064

[2] Dutczak, J. Micro turbine engines for drones propulsion. In IOP Conference Series: Materials Science and Engineering, 2016. 148, 012063. doi: 10.1088/1757-899X/148/1/012063

[3] Balli, O. Failure analysis of inlet guide vane (IGV) actuator and bellcrank assembly used on J85 turbojet engines. Engineering Failure Analysis. 2020. Vol. 115, Paper No. 104700, doi: 10.1016/j.engfailanal.2020.104700

[4] Fozo L. et al. Evaluation of the Operational State of a Small Turbojet Engine Using Variations in Its Near Magnetic Field. Acta Physica Polonica A. 2020. Vol. 137, No. 5, pp. 670-673, doi: 10.12693/APhysPolA.137.670

[5] Waligorski, M. - Batura, K. - Kucal, K. - Merkisz, J. Empirical assessment of thermodynamic processes of a turbojet engine in the process values field using vibration parameters. Measurement. 2020. Vol. 158, paper no. 107702, doi: 10.1016/j.measurement.2020.107702

[6] Andoga R. et al. Intelligent Thermal Imaging-Based Diagnostics of Turbojet Engines. Applied Sciences - Basel. 2019. Vol. 9, No. 11, doi: 10.3390/app9112253

[7] Beneda K. Development of a modular FADEC for small scale turbojet engine. In IEEE 14th International Symposium on Applied Machine Intelligence and Informatics (SAMI), Herl'any, 2016. doi: 10.1109/SAMI.2016.7422981

[8] NXP MC9S08DZ60 HCS08 microcontroller data sheet. Available at: https://www.nxp.com/docs/en/data-sheet/MC9S08DZ60.pdf

[9] NXP KE06 Sub-Family Data Sheet. Available at: https://www.nxp.com/docs/en/datasheet/MKE06P80M48SF0.pdf

Received 06, 2021, accepted 07, 2021

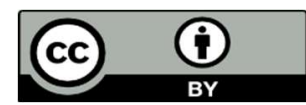

Article is licensed under a Creative Commons Attribution 4.0 International License 